\title{
An extrahepatic biliary atresia (EHBA) mimic- a case report
}

\author{
Hemlata Singh ${ }^{1}$, Bhavika Y M², Ramkesh Meena ${ }^{3}$, Vivek Dewan ${ }^{4}$ \\ ${ }^{1}$ Dr. Hemlata Singh, Senior Resident, Paediatrics, ${ }^{2}$ Dr. Bhavika Y. M, PG Resident, ${ }^{3}$ Dr. Ramkesh Meena, \\ Senior Resident, ${ }^{4}$ Dr. Vivek Dewan, Professor, MD Paediatrics, all authors are affiliated with Department of \\ Paediatrics, PGIMER \& Dr RML Hospital, New Delhi, India.
}

Address for Correspondence: Dr Hemlata Singh, Department of Pediatrics, PGIMER and Dr RML Hospital, Baba Kharak Singh Marg, New Delhi, India. E-mail: drhema.rml@gmail.com

\begin{abstract}
Extra hepatic biliary obstruction is surgically correctable cause of neonatal cholestasis, with good outcome if operated within 6 weeks. We report a case mimicking biliary atresia clinically and on imaging (HIDA, MRCP) and had complete resolution after exploratory laparotomy. Per-operatively, bile ducts were found to be patent; subsequently patient's bilirubin status and liver functions improved and child has been thriving well. Preoperative liver biopsy showed patent ducts with findings of cholestasis.
\end{abstract}

Key words: neonatal cholestasis, MRCP. bile plug, EHBA

\section{Introduction}

EHBA is one of the most commonly encountered causes of neonatal cholestasis with a prevalence of 1 in 15000-20000. With latest imaging techniques it is relatively easier to differentiate it from neonatal hepatitis and confirm with liver biopsy. Most patients (85\%-90\%) have progressive postnatal obliteration of bile ducts requiring early surgical correction. We report a case presenting as EHBA clinically, biochemically, sonographically and on imaging, however, preoperatively on saline flushing, had a patent biliary system with relief of mechanical obstruction.

\section{Case Report}

A two months male child admitted with progressively increasing jaundice since 10 days of life and passing white/pale stools since birth. There was no fever, vomiting, irritability, seizures, bleeding manifestations. He was born at term with uneventful antenatal and perinatal period. Child was hemodynamically stable with deep icterus and hepatomegaly with liver span of $7 \mathrm{~cm}$, but had no features of liver cell failure or facial dysmorphism. Fundus was normal, spleen was not palpable and other system examination within normal limits. Investigations revealed conjugated hyperbilirubinemia (total bilirubin- 13 , direct- $5 \mathrm{mg} / \mathrm{dl}$ ) and deranged liver enzymes (SGOT-258 /SGPT- $168 \mathrm{U} / \mathrm{L})$, total alkaline phosphatase (369 U/L) and GGT level (178 U/L). Serum proteins $(5.5 \mathrm{mg} / \mathrm{dl}), \mathrm{S}$. albumin $(3.9 \mathrm{mg} / \mathrm{dl})$, and coagulation profile was normal. Other investigations showed negative TORCH profile, absence of reducing substances in urine, non-reactive viral markers (HBsAg/HAV/HCV/HEV), normal TMS screen, normal levels of alpha-1 antitrypsin and sweat chloride, normal lipid and thyroid profiles.

Ultrasonography showed normal liver echotexture with contracted gall bladder, normal portal vein size and distal CBD was not visualised. HIDA scan was suggestive of biliary outflow obstruction. MRCP showed a diffusely narrowed common bile duct in mid-portion. Inevitably, EHBA was considered as diagnosis. Exploratory laparotomy and open liver biopsy was done but preoperatively, after flushing of biliary tract, findings were inconsistent with biliary atresia and cholestasis; biopsy was taken for confirmation. Liver biopsy showed ballooning feathery degeneration and giant cell canalicular cholestasis, rosette formation, focal bile

Manuscript received: $2^{\text {nd }}$ June 2017

Reviewed: $12^{\text {th }}$ June 2017

Author Corrected: $21^{\text {st }}$ June 2017

Accepted for Publication: $28^{\text {th }}$ June 2017 
lakes, focal sinusoidal dilation with prominence of kupffer cells with few showing lipofuschin pigment and few acidophilic bodies consistent with neonatal cholestasis. Postoperatively, patient had improving trends of hyperbilirubinemia and gradual resolution of bilirubin was documented within few days of laparotomy. At 3 month follow up, a consistent weight gain was observed along with normal LFT (Total- $0.4 \mathrm{mg} / \mathrm{dl}$; Direct-0.1 mg/dl; SGOT-22 U/L; SGPT-28 U/L; GGT- 20 U/L).

\section{Discussion}

Biliary atresia (BA) is an ascending inflammatory process of biliary tree leading to biliary cirrhosis. Hence rapid identification of BA is crucial [1]. HIDA scan (hepatobiliary sequence scintigraphy) has a high sensitivity $(83-100 \%)$ but lacks specificity in many cases $(33-80 \%)$, limiting its usefulness to differentiate between BA and other non-surgical conditions [2]. Magnetic resonance cholangiopancreatography (MRCP) is a widely accepted method of imaging the biliary system.

The diagnostic value of MRCP for EHBA is 82 $98 \%$, with sensitivity of $90-100 \%$, and specificity of $77-96 \%$ [3]. In our patient, on the basis of HIDA and MRCP a diagnosis of biliary atresia was kept and patient was referred for surgery to avoid further delays but paradoxically no evidence of atresia was found peroperatively. The plausible explanation could be dislodgement of a bile plug or breaking of any thin membrane and drainage via the bile duct. We could not ascertain an alternative diagnosis for this presentation. Child is on follow up in special clinic and is thriving well with no jaundice and normal liver functions. This kind of presentation of biliary atresia mimic as a result of mechanical block possibly due to mucus plug or membrane has never been reported in the literature to the best of our knowledge.

\section{Conclusion}

EHBA is a surgical emergency but atypical presentation such as in this case where spontaneous remission was seen, builds up the curiosity to identify additional pathogenetic mechanism that might explain such presentations and defer radical surgeries.

Abbreviations: EHBA- extrahepatic biliary obstruction; HIDA- hepatobiliary iminodiacetic acid; MRCP- magnetic resonance cholangiopancreaticography

Conflict of Interest: authors and co-authors have no conflict of interest to disclose

Financial disclosures: the authors and co-authors have no financial relationships relevant to this to disclose.

Funding: Nil, Conflict of interest: None initiated, Perission from IRB: Yes

\section{References}

1. Mack CL, Sokol RJ. Unraveling the pathogenesis and etiology of biliary atresia. Pediatr Res. 2005 May;57(5 Pt 2):87R-94R.

2. Bérard E, Sarles J, Triolo V, Gagnadoux MF, Wernert F, Hadchouel M, Niaudet P. Renovascular hypertension and vascular anomalies in Alagille syndrome. Pediatr Nephrol. 1998 Feb;12(2):121-4.

3. Yang J, Ma D, Peng Y, Song L, Li C. Comparison of different diagnostic methods for differentiating biliary atresia from idiopathic neonatal hepatitis. Clinical Imaging. 2009; 33(6): 439-446.

\section{How to cite this article?}

Hemlata Singh, Bhavika Y M, Ramkesh Meena, Vivek Dewan. An extrahepatic biliary atresia (EHBA) mimica case report. J PediatrRes.2017;4(06):361-362.doi:10.17511/ijpr.2017.i06.02. 